\title{
UMA ESTRANHA DESCOBERTA: LEITURA dO CONTO "A MENOR MULHER dO MUNDO", de Clarice Lispector
}

\author{
Yudith Rosenbaum
}

Universidade de São Paulo

Resumo

O presente artigo pretende analisar o conto "A menor mulher do mundo", de Clarice Lispector, à luz do ensaio "O estranho", de Freud. A ideia é compreender as relações de dominação que se estabelecem entre um explorador francês e sua insólita descoberta na África Equatorial: uma pigmeia grávida. Partindo desse jogo de alteridades, que se estranham e se identificam, a análise buscará desvelar algumas camadas de sentido tendo como pano de fundo a dinâmica entre cultura e pulsão, recalque e desejo. A história dos processos coloniais brasileiros e a história da constituição do sujeito humano se entrecruzam nessa narrativa, que desloca formas habituais de posicionar o eu diante do outro. O efeito irônico do texto se dá ao inverter as expectativas nesse encontro entre a ordem selvagem e a ordem doméstica, descortinando nesta última reações perversas imprevistas.

\section{Abstract}

This article intends to analyze Clarice Lispector's short story "A menor mulher do mundo" according to Freud's essay "The uncanny". We want to understand the domination relationship between a French explorer and his uncanny discovery in Equatorial Africa: a pregnant Pigmee. An interplay of alterities, estranging and identified between themselves, will open the way for an analysis that will try to unveil some levels of meaning against a background that puts in a dialectical relationship culture and impulse. The history of Brazilian colonization and the history of the constitution of the human subject are intermingled in this story, that dislocates habitual forms of positioning the ego in relation to the other. The text's ironical effect appears when an inversion of expectations occur between the savage and the domestical orders, revealing surprising and perverse reactions in the latter.

\section{Palavras-chave}

Clarice Lispector, unheimliche, alteridades, cultura.

\section{Keywords}

Clarice Lispector, unheimliche, alterities, culture. 
Continuo convencido de que a mente humana, assim como a totalidade da pessoa humana está na pré-história, em um elo inferior a suas possibilidades.

\section{Júlio Cortázar}

Desde sua estreia, com o romance Perto do coração selvagem, em 1944, Clarice Lispector parece destinada a perturbar seus leitores. Ao criar um campo de sentidos dissonantes e avessos aos hábitos comuns, é uma autora que tem muito a nos dizer sobre o bizarro e sua imprevista beleza a partir da arte ficcional. Seus textos nos atraem justamente por construir um território insólito e estranho, destoando do belo asséptico e purificado - predominante na arte clássica. O que captura o olhar de Clarice, e por consequência o do leitor, não é o consagrado ou canônico, nem o hegemônico ou convencional, mas formas de vida desviantes, retorcidas, deslocadas, marginais ao bom senso e ao senso comum, gerando perplexidade e sinistros encantamentos.

Sua mirada se inclina, por vocação, ao que falha como projeto harmônico. Ou nas palavras da própria autora: "Gosto de um modo carinhoso do inacabado, do malfeito, daquilo que tenta desajeitadamente um pequeno vôo e cai sem graça no chão". ${ }^{1}$ E é nesse chão surrado e disforme que são colhidas inquietantes estranhezas da natureza humana mais esquiva.

Para olhar de perto esse estranho território, proponho então um breve percurso pelo conto "A menor mulher do mundo", publicado em 1959 na Revista Senhor, editada na época por Paulo Francis, e depois recolhido no volume Laços de família, de $1960 .^{2}$ Desenredando os fios que compõem esse texto, talvez se possa observar em detalhe o campo obscuro do que foi renegado pela cultura, pelo chamado "mundo administrado" (nos termos adornianos) e que retorna sob a figura do espantoso, desafiando os hábitos construídos. A noção de "Unheimliche" freudiana será o fio condutor desta análise, uma vez que permite compreender o jogo textual entre cultura e recalque, um dos fundamentos dessa narrativa. Através da experiência de "Unheimliche" - que, como se sabe pelo conhecido ensaio de Freud, ${ }^{3}$ remete ao que já foi familiar e conhecido, tornando-se estranho por efeito da repressão e que retorna sob a forma do insólito - a literatura de Clarice enreda o leitor em uma dinâmica ao mesmo tempo perturbadora e reveladora.

$* * * * * * *$

O conto relata uma descoberta feita por um explorador francês, de nome Marcel Pretre ("caçador e homem do mundo"), nas profundezas da África Equatorial, no interior do Congo Central. Penetrando ainda mais fundo nas florestas, Marcel Pretre "topou com uma tribo de pigmeus de uma pequenez surpreendente". E mais adiante: "[...] como uma caixa dentro de uma caixa, dentro de uma caixa - entre os menores pigmeus do mundo estava o menor dos menores pigmeus do mundo, obedecendo talvez à necessidade que às vezes a Natureza tem de exceder a si própria". ${ }^{4}$ Entre eles, Marcel Pretre defronta-se com uma mulher de quarenta e cinco centímetros, "madura, negra, calada. 'Escura como um macaco', informaria ele à imprensa". ${ }^{5}$ Ficamos sabendo, ainda, que a menor das pigmeias estava grávida. Em seguida, diz o narrador:

${ }^{1}$ LISPECTOR, Clarice. "Fundo de gaveta". In: A Legião Estrangeira. Rio de Janeiro: Edição do Autor, 1964, p. 127.

${ }^{2}$ LISPECTOR, Clarice. Laços de Família. 24. ed. Rio de Janeiro: Francisco Alves, 1991.

${ }^{3}$ FREUD, Sigmund. "O Estranho". In:

${ }^{4}$ LISPECTOR, op. cit., 1991, p. 87.

${ }^{5}$ Ibidem. . Obras Completas. Rio de Janeiro: Imago, 1976, vol. XVII. 
Na certa, apenas por não ser louco, é que sua alma não desvairou nem perdeu os limites. Sentindo necessidade imediata de ordem, e de dar nome ao que existe, apelidou-a de Pequena Flor. E, para conseguir classificá-la entre as realidades reconhecíveis, logo passou a colher dados a seu respeito. ${ }^{6}$

Nesses poucos parágrafos, já está armado o jogo matricial da narrativa clariciana: o encontro de alteridades que se estranham, se identificam e se repelem. Aqui é o esquisito de uma pigmeia, gestando provavelmente o menor dos bebês pigmeus, em confronto com um cientista cartesiano, impactado por algo inominável. Para não desvairar com o choque de uma realidade inapreensível e não familiar, Marcel Pretre recorre à taxonomia botânica, zoológica ou pseudocientífica para reassegurar seu lugar de civilidade diante da experiência selvagem: sua incrível descoberta é assemelhada aos bichos ("escura como um macaco"), depois aos vegetais ("pequena flor") e por fim aos minerais ("esmeralda nenhuma é tão rara"). ${ }^{7}$

Os dados coletados mostram que Pequena Flor pertence aos Likoualas, uma raça em extinção ameaçada pelos bantos, que os comem. ${ }^{8}$ Diz o texto: "A racinha de gente, sempre a recuar e a recuar, terminou aquarteirandose no coração da África.” A linguagem dos Likoualas é breve e simples, reduzida ao essencial. O processo descrito em gradação para trás (“sempre a recuar") parece caminhar da superfície ao núcleo. Algo se desloca em direção ao centro, ao coração selvagem da vida. Note-se que o tom do discurso do narrador promove, inicialmente, um distanciamento "objetivo", "científico" em relação a essa espécie rara, oferecendo ao leitor a possibilidade de mirar-se no espelho desse outro tão diverso sem, no entanto, ser invadido por ele. Olhamos por cima esse ser da floresta, mas aos poucos a "racinha de gente" vai se revelando ser também a nossa.

E frente à "estranha graça" da "coisa humana menor que existe", como reage a cultura dominante do cientista? "Ali estava uma mulher que a gulodice do mais fino sonho jamais pudera imaginar", diz o texto em chave irônica. Trata-se, portanto, de um objeto de desejo (ou de repulsa?) inimaginável de tão diferente, sem os contornos conhecidos e habituais. A ele somos atraídos, como parece ser o cientista do conto; também como ele, nos defendemos desse mesmo objeto com artifícios racionalizadores.

Reconhecemos nesse modo de antepor um sujeito - supostamente superior - em frente de um objeto depreciado, a matriz dos processos de dominação e exploração do outro, seja da história colonial brasileira, seja das relações interpessoais mais cotidianas. ${ }^{9} \mathrm{O}$ conto contempla a macro e a micro história,

${ }^{6}$ LISPECTOR, op. cit., 1991, p. 88.

${ }^{7}$ Cf. Berta Waldman em ensaio sobre o mesmo conto: "Depois de zoomorfizar sua descoberta (macaco) e de transformá-la em flor, ele encontrará uma afinidade entre 'a coisa humana menor que existe' e o mundo mineral, ao dizer que ela era 'mais rara que qualquer esmeralda""،. (WALDMAN, Berta. "Duas mulherzinhas". In: presença judaica na literatura brasileira. São Paulo: Perspectiva, 2001, p. 63).

Entre passos e rastros:

${ }^{8}$ De fato, alguns estudos antropológicos sobre os grupos de pigmeus africanos relatam as perseguições dos Bantos, como se lê nesta descrição: "Na República do Congo, onde pigmeus representam 5 a 10\% da população, muitos pigmeus vivem como escravos de mestres Bantos. A nação está profundamente dividida entre estes dois grandes grupos étnicos. Os pigmeus escravos pertencem desde o nascimento até à sua morte aos mestres Bantos em um relacionamento que os Bantos chamam de honrada tradição. Chegam a ser considerados parte do seu patrimônio familiar e, como tais, são transmitidos como herança de geração em geração" (MEGAARQUIVO. 10.085 - Antropologia - Os pigmeus. Disponível em: < http:// megaarquivo.com/2014/04/15/10-085-antropologia-os-pigmeus/>. Acesso em: 28 ago. 2015.). Escravidão e dominação, portanto, penetram no conto pela via etnológica dos grupos em conflito, fundindo ficção e antropologia.

${ }^{9}$ No ensaio já citado, Berta Waldman recorre à teoria crítica para situar a operação discriminatória que encarcera o outro em sua angustiante diferença: "Theodor Adorno, em Mínima Moralia, numa das partes em que trata do nazismo, afirma que o esquema social de percepção dos anti-semitas está configurado de tal modo que não lhes permite ver os judeus como homens. A tão divulgada afirmação de que os selvagens, os negros, os judeus ou os japoneses parecem animais, quase macacos, contém já a chave do pogrom (grifo da autora).O passo seguinte é por em prática um programa de extermínio sistemático e impessoal para subjugar e desumanizar o homem de modo que os executores sejam persuadidos de estarem abatendo "não mais que animais" ou "somente animais", enquanto enxergam como homens apenas o reflexo de sua própria imagem, sem nenhum linha de fuga que acena para a diferença" (WALDMAN, op. cit., p. 65). 
pois na primeira parte, como vimos, o colonizador busca dissecar sua descoberta, submetendo-a aos padrões culturais familiares e hegemônicos, negando sua estranha humanidade ao erigir uma diferenciação clara entre ele e o outro; já na segunda parte do conto, a fotografia de Pequena Flor é publicada no jornal dominical, "onde coube em tamanho natural" - enrolada num pano para esconder o sexo, com a barriga em estado adiantado - o que faz circular pelas famílias burguesas a vivência desse Unheimliche perturbador. ${ }^{10}$

Com uma câmera na mão, o narrador invade os lares comportados da classe média e traz à tona as reações mais inesperadas (ou nem tanto?) no contato com Pequena Flor, multiplicando, portanto, o jogo das alteridades. Agora é o leitor quem vivencia o estranhamento, a sensação de mal-estar ao ler os que leem a notícia, abrindo mais uma das caixas dentro da caixa. No primeiro apartamento, uma mulher desvia os olhos, aflita; em outro:

[...] uma senhora teve tal perversa ternura pela pequenez da mulher africana que - sendo melhor prevenir do que remediar - jamais se deveria deixar Pequena Flor sozinha com a ternura da senhora. Quem sabe a que escuridão de amor pode chegar o carinho. ${ }^{11}$

A perversidade parece deslocar-se do lugar onde se esperaria encontrá-la - a selva africana - e passa a habitar perigosamente nossos lares. O tom irônico do texto desvenda os bichos humanos em sua nudez grotesca. É o que vemos em outra casa, onde "um menino esperto teve uma ideia esperta":

— Mamãe, se eu botasse essa mulherzinha africana na cama de Paulinho, enquanto ele está dormindo? Quando ele acordasse, que susto, hein! Que berro, vendo ela sentada na cama! E a gente então brincava com ela! A gente fazia ela o brinquedo da gente, hein! ${ }^{12}$

A reificação sádica é apenas mais uma das reações reveladoras de um núcleo selvagem recôndito, que vem à luz - como "uma caixa dentro da caixa dentro da caixa" - em cada uma das casas visitadas pelo narrador. Inevitável abrirmos esta metáfora minimalista, que faz de Pequena Flor uma espécie de fóssil arqueológico perdido, esqueleto esquecido e recalcado, do qual nos distanciamos no processo de aculturação e para o qual Clarice Lispector nos conduz com olhos míopes ${ }^{13}$. A mínima vida da diminuta pigmeia, na qual lateja um proto sujeito elementar e primário, se agiganta pela minúcia descritiva do narrador.

\footnotetext{
${ }^{10}$ Não deixa de ser curioso o fato de que o processo de criação deste conto reedite em mise en abîme "uma caixa dentro de uma caixa dentro de uma caixa", já que a autora teria lido, ela mesma, uma notícia de jornal sobre uma pigmeia. Ela transpõe para o texto o enquadre que diz respeito à referencialidade externa a ele. Em nota explicativa sobre a origem desse conto, Clarice menciona uma notícia de jornal que teria lido em Washington onde morava na época: ““A Menor Mulher do Mundo' me lembra domingo, primavera em Washington, criança adormecendo no colo no meio de um passeio, primeiros calores de maio - enquanto a menor mulher do mundo (uma notícia lida no jornal) intensificava tudo isso num lugar que me parece o nascedouro do mundo: África. Creio que este conto vem de meu amor por bichos: parece-me que sinto os bichos como uma das coisas ainda muito próximas de Deus, material que não inventou a si mesmo, coisa ainda quente do próprio nascimento; e, no entanto, coisa já se pondo imediatamente de pé, e vivendo toda, e em cada minuto vivendo de uma vez, nunca aos poucos apenas, nunca se poupando, nunca se gastando" (p. 175-176). O fato atribui ao texto uma dimensão realista que tensiona seu caráter ficcional, potencializando o jogo entre real e imaginário, tão marcante na obra da autora. O testemunho documental da autora sobre a origem do conto, de todo modo, é transfigurado pela linguagem literária, deixando visíveis poucas e disfarçadas marcas do contexto em que foi gerado.

${ }^{11}$ LISPECTOR, op. cit., 1991, p. 90.

${ }^{12}$ LISPECTOR, op. cit., 1991, p. 91.

${ }^{13}$ Utilizo aqui a expressão cunhada por Gilda de Mello e Souza (“O vertiginoso relance”. In: Exercícios de leitura. São Paulo: Duas Cidades, 1980, p. 79-91). Analisando a escrita clariciana da perspectiva do olhar feminino, da "vocação da minúcia", do apego ao detalhe do que lhe é próximo, a ensaísta afirma: "A visão que constrói é por isso uma visão de míope, e no terreno que o olhar abrange, as coisas muito próximas adquirem uma luminosa nitidez de contornos" (p. 79).
} 


\title{
Estranhas maternidades
}

Mas de todas as cenas domésticas descritas, uma ganha relevo especial pelo seu teor mórbido e abjeto. A mãe do menino esperto observa-se ao espelho e lembra-se do que lhe contara a cozinheira nos tempos do orfanato:

\begin{abstract}
Não tendo boneca com que brincar, a maternidade já pulsando terrível no coração das órfãs, as meninas sabidas haviam escondido da freira a morte de uma das garotas. Guardaram o cadáver num armário até a freira sair, e brincaram com a menina morta, deram-lhe banhos e comidinhas, puseram-na de castigo somente para depois poder beijá-la, consolando-a. Disso a mãe se lembrou no banheiro, e abaixou mãos pensas, cheias de grampos. E considerou a cruel malignidade de nosso desejo de ser feliz. Considerou a ferocidade com que queremos brincar. E o número de vezes em que mataremos por amor. Então olhou para o filho esperto como se olhasse para um perigoso estranho. E teve horror da própria alma que, mais que seu corpo, havia engendrado aquele ser apto à vida. ${ }^{14}$
\end{abstract}

Definitivamente, Lispector não nos poupa de uma visão repugnante da intimidade doméstica de uma mãe comum. Sua escrita descortina o que teimamos em ocultar. Ao desmascarar a cruel malignidade de nosso modo de amar, a ferocidade de nosso prazer - modos paradoxais de existirmos -, a autora também nos permite reconhecer a humanidade falha que nos constitui. Se olharmos de perto esse longo trecho, veremos a sobreposição de maternidades, mais uma vez a imagem de uma caixa dentro de uma caixa: a mãe pigmeia, as meninas mães do orfanato, a mãe que se olha no espelho. Tantos jeitos de viver a mesma função biológica - desde aquela que está mais aderida à natureza, a mulher africana, até a carência perversa das órfãs, passando pela perplexidade com a própria cria da mãe ao espelho. Ao mirar-se, "a mãe sorriu intencionalmente fina e polida, colocando, entre aquele seu rosto de linhas abstratas e a cara crua da Pequena Flor, a distância insuperável de milênios" (p. 92). A modernidade surge como abstração de uma crueza, esta sim pulsante e vital, condensada na figura da pigmeia. Assim, é do abjeto enquanto magma primordial, morada informe de nossa ancestralidade, mundo pulsional de um fundo sem fundo, que o sujeito humano se distancia para se constituir, perdendo sua carnalidade, tornando-se abstrato, ou seja, genérico, alienado de sua singularidade. Mas nas frinchas das aparências cívicas e polidas, os traços de tantas abjeções revivem e nos relembram quem somos.

Ainda no trecho comentado acima, é possível perceber um terceiro círculo de estranhamento - agora da mãe em relação ao seu próprio filho - que se junta aos dois anteriores: Marcel Pretre diante da pigmeia e os leitores dos jornais frente à insólita notícia. Mas, já notado, é possível vislumbrar ainda o quarto círculo que somos nós diante do texto. Como o ponto de vista do narrador é móvel, circulando pela perspectiva do explorador francês, depois deslocando-se para a pigmeia e também pelos olhares dos leitores da notícia, o efeito da inquietante estranheza perpassa, portanto, vários níveis narrativos. Relativizam-se as visões absolutas. Problematizam-se as ideologias. A desmontagem do registro habitual, fruto dos procedimentos de linguagem aqui presentes, é o resultado alcançado pela autora. Ao estranharmos o conto, revisitamos nosso próprio campo subjetivo, confrontando a acomodação (nossa e das famílias que leem) com a experiência que desterritorializa. ${ }^{15}$

${ }^{14}$ LISPECTOR, op. cit., 1991, p. 91.

${ }^{15}$ Refiro-me aqui ao conceito de "desterritorialização" de Gilles Deleuze, desenvolvido inicialmente na obra Anti-Édipo (1972), com Félix Guatarri, e que se insere numa trama bem mais complexa de outras noções como territorialização, reterritorialização, ritornelo, rizoma, linhas de fuga e devir, entre outras, avançando para novas configurações ao longo da obra do filósofo. Ao que nos interessa, retemos a ideia de um deslocamento de certo território onde o sujeito se insere, desmontando uma codificação prévia. Trata-se de uma experiência existencial próxima ao estranhamento freudiano, mas que não se confunde com ela. Quando Deleuze analisa a obra de Kafka, refere-se à relação do autor tcheco com a língua alemã, onde desterritorializar implicaria fluxo de intensidades em linhas de fuga. Nas suas palavras, Kafka explora uma "sintaxe do grito, que esposará a sintaxe rígida desse alemão ressecado. Empurrar-se-lhe-á até uma desterritorialização que não será mais compensada pela cultura ou pelo mito, que será uma desterritorialização absoluta, mesmo que ela seja lenta, colante, coagulada. Levar lentamente, progressivamente, a língua para o deserto. Servir-se da sintaxe para gritar, dar ao grito uma sintaxe" (DELEUZE, Gilles; GUATARRI, Féliz. Kafka. Por uma literatura menor. Trad. Cintia Vieira da Silva, revisão de Luis Orlandi. Belo Horizonte: Autêntica, p. 52, 2014). 
A ressonância de Pequena Flor no mundo familiar prossegue por mais algumas casas: "No coração de cada membro da família nasceu, nostálgico, o desejo de ter para si aquela coisa miúda, aquela fonte permanente de caridade" (p. 92); ou ainda: "— Deve ser o bebê preto menor do mundo - respondeu a mãe, derretendo-se de gosto. - Imagine só ela servindo a mesa aqui em casa! E de barriguinha grande!” (p. 93). Desejo de posse, preconceito racial, exploração do trabalho alheio e tantas outras manifestações cruas e selvagens mostram que duas ordens se confrontam: uma doméstica, marcada pela habituação cultural, cuja nobreza se revela falseadora de sua real natureza; outra, da barbárie, que lateja sob o verniz social. O mal estar da cultura ${ }^{16}$, expressão que a psicanálise cunhou para condensar a dialética entre a demanda do sujeito e o imperativo do mundo, ronda a narrativa e impregna as reações de seus agentes, incluindo entre elas o leitor e seu incômodo.

O conto se iniciou na floresta africana e depois migrou para o cenário da cidade, trazendo a natureza selvagem para o interior das famílias urbanas. A violência, como se pode ver, colocou-se inteiramente do lado destas, quebrando as expectativas banais de um leitor desavisado. Sem dúvida, essa é a intenção desalienante da ficção clariciana, rompendo ideologias e representações paralisantes. O cenário, antes longínquo e exótico da selva equatorial, ganha imprevista proximidade e escancara o que se ocultava na mata escura da cidade.

\section{O Outro, esse inclassificável}

Ainda há um terceiro movimento narrativo. A câmera se desloca agora da selva urbana ao ambiente africano, onde o explorador examina metodicamente a barriguinha do menor ser humano maduro. Diz o texto:

Foi neste instante que o explorador, pela primeira vez desde que a conhecera, em vez de sentir curiosidade ou exaltação ou vitória ou espírito científico, o explorador sentiu mal-estar. É que a menor mulher do mundo estava rindo. Estava rindo, quente, quente. Pequena Flor estava gozando a vida. A própria coisa rara estava tendo a inefável sensação de ainda não ter sido comida" [...] Era um riso como somente quem não fala ri. Esse riso, o explorador constrangido não conseguiu classificar. ${ }^{17}$

O gozo da vida constrange e ameaça. E talvez a palavra "Unheimliche" seja o modo de (in) definir esse riso sem fala, esse eu sem máscara, sem mediações, reduzido a si mesmo. Não tendo outros recursos, diz o texto, Pequena Flor estava "reduzida às profundezas". O paradoxo da profundidade que se revela como superfície talvez seja uma das marcas claricianas. $\mathrm{O}$ dentro e o fora se confundem e as fronteiras conhecidas perdem seus contornos. Já não há um externo ao qual se opõem um interno. Entre a casca e o interior pode haver pouca distância. Ou melhor, a casca pode ser o próprio interior. O que importa é a busca do que antecede a forma, seja ela qual for.

Como na saga de G.H. diante da massa branca da barata no romance A Paixão Segundo G.H., de Clarice Lispector (1964), trata-se de entrar em contato com o inexpressivo, com a vida de grau quase zero, com esse aquém da linguagem onde as coisas ainda não se tornaram signos. E esse outro, tanto em G.H. quanto no conto, mobiliza um jogo especular sinistro ao devolver aos "bem formados" uma

16 “É impossível desprezar o ponto até o qual a civilização é construída sobre uma renúncia ao instinto, o quanto ela pressupõe exatamente a não satisfação (pela opressão, repressão, ou outro meio?) de instintos poderosos. Essa 'frustração cultural' domina o grande campo dos relacionamentos sociais entre os homens". Cf. FREUD, Sigmund. "O mal-estar na civilização.” In: _. Obras completas. Rio de Janeiro: Imago, v. XXI, 1974, p. 118.

${ }^{17}$ LISPECTOR, op. cit., 1991, p. 93, 94. 
imagem distorcida e repugnante de si mesmos, potência desordenadora que deve ser neutralizada pela ciência reificadora.

No caso do romance, G.H. se deixa transformar pela experiência da abjeção, reconhecendo, ao preço de uma desconstrução sacrificial de si e da linguagem egoica, a necessidade de banhar-se na matéria primordial da vida. "Para ter chegado a isso", diz a narradora G.H., "eu abandonava a minha organização humana - para entrar nessa coisa monstruosa que é a minha neutralidade viva" ${ }^{18}$. Na aventura desta pacata dona-de-casa, que tem início ao arrumar o quarto de empregada na cobertura chique de um edifício carioca, não é possível esquivar-se do confronto com a sua sombra degradante. E a cada nova aproximação, diferentemente do explorador francês com sua criatura, todo o mundo vivo de G.H. é ressignificado e a sua vivência é a de um novo nascimento:

O neutro é inexplicável e vivo, procura me entender: assim como o protoplasma e o sêmen e a proteína são de um neutro vivo. E eu estava toda nova, como uma recém-iniciada. Era como se antes eu estivesse estado com o paladar viciado por sal e açúcar, e com a alma viciada por alegrias e dores - e nunca tivesse sentido o gosto primeiro. E agora sentia o gosto do nada. Velozmente eu me desviciava, e o gosto era novo como o do leite materno que só tem gosto para boca de criança. Com o desmoronamento de minha civilização e de minha humanidade - o que me era um sofrimento de grande saudade - com a perda da humanidade, eu passava orgiacamente a sentir o gosto da identidade das coisas. ${ }^{19}$

Voltando ao conto, Pequena Flor por dois momentos desconcerta a visada defensiva de Marcel Pretre. Na primeira, ao ser nomeada pelo homem, ela "se coça onde pessoa não se coça", fazendo o explorador desviar os olhos. Na segunda, ao ter sua barriguinha examinada por ele, Pequena Flor ri, como se viu acima. "Enquanto ela não estava sendo comida", diz o texto, "seu riso bestial era tão delicado como é delicada a alegria. O explorador estava atrapalhado" (p. 94). É pela ironia sutil da narração que testemunhamos o apequenamento desse representante da cultura europeia frente ao aborígene "atrasado". Ou ainda o confronto bizarro e desigual entre o masculino e o feminino. O conto desconstrói a ideologia que teima em sustentar a face perversa da discriminação. Pequena Flor não se rende ao olhar quantificador de Marcel Pretre. Na verdade, ela "amava aquele explorador amarelo", mas também amava muito seu anel, sua bota:

Mas na umidade da floresta não há desses refinamentos cruéis, e amor é não ser comido, amor é achar bonita uma bota, amor é gostar da cor rara de um homem que não é negro, amor é rir de amor a um anel que brilha. Pequena Flor piscava de amor, e riu quente, pequena, grávida, quente. ${ }^{20}$

Novamente Clarice Lispector "desdicionariza" a palavra "amor" (como já havia feito no conto “Amor”, de Laços de família), amplificando seus paradoxos e eliminando hierarquias de uma construção imaginária que idealiza o amor romântico. Aqui, o amor da pigmeia se estende sem fronteiras, abarcando tudo o que vem do outro.

Marcel Pretre ainda tentou retribuir o sorriso, num átimo de desnudamento e entrega amorosa, mas disfarçou e corou pudico. "Foi provavelmente ao ajeitar o capacete simbólico que o explorador se chamou à ordem, recuperou com severidade a disciplina de trabalho, e recomeçou a anotar" (p. 95).

A grande inversão do conto parece ser justamente essa: a suposta interioridade do colonizador ocidental se anula frente à profundidade explícita da pigmeia e se torna pura exterioridade

\footnotetext{
${ }^{19}$ Ibidem, p. 99.

${ }^{20}$ LISPECTOR, op. cit., 1991, p. 95.
} 
(metaforizada no capacete protetor), ao passo que Pequena Flor, a quem não atribuiríamos sequer uma subjetividade, habita uma intimidade aberta e plena, despojada de capacetes e de símbolos. A humanidade que nela pulsa precisa resistir às anotações classificatórias do cientista, que busca animalizar sua descoberta africana e afastar do convívio humano essa cruel alteridade ${ }^{21}$. Ao corar pudico, o cientista revela-se mais vulnerável aos afetos do que faria supor seu "capacete simbólico". Ele se deixa atingir, pelo menos por um instante, pelo desejo fugaz que o piscar amoroso da pigmeia suscita. O que nele se mostrava pura racionalidade ganha um novo colorido para o leitor, desfazendo, de algum modo, as fronteiras demarcadas pelo narrador até então. Marcel Pretre, afinal, pode corar, constranger-se, tentar sorrir. A pigmeia e o explorador podem intercambiar papéis na narrativa, estranhar-se mutuamente, usufruir por um átimo a alteridade que cada um representa para o outro. O conto flagra justamente essa frincha fugaz, instante em que somos humanamente iguais nas diferenças.

A utopia clariciana, nesta e em várias narrativas, é a de que possamos recolher pequenas flores em nossos jardins já tão cultivados, resgatando uma vida oblíqua e primordial. Sua escrita é um espaço de abertura ao desconhecido, ao encontro com o acaso e o inesperado.

O final do conto pede ainda alguns comentários finais:

Marcel Pretre teve vários momentos difíceis consigo mesmo. Mas pelo menos ocupou-se em tomar notas. Quem não tomou notas é que teve de se arranjar como pode:

- Pois olhe - declarou de repente uma velha fechando o jornal com decisão —, pois olhe, eu só lhe digo uma coisa: Deus sabe o que faz. ${ }^{22}$

De onde fala esse narrador que ironiza tanto o cientista e seus "momentos difíceis consigo mesmo", dando a ele a patética possiblidade de ao menos tomar notas? Qual é a perspectiva dessa voz narrativa que também ridiculariza os que, sem anotar, renderam-se ao salvador? O ponto de vista é crítico, sem dúvida, até cáustico ao se referir à frágil defesa das notações científicas e também ao refúgio na religião. A experiência da vida escapa às palavras, às tabelas, ao intelecto conformador, ao credo divino. Lembremos o fragmento "O uso do intelecto", em A descoberta do mundo - reunião das crônicas de Clarice Lispector publicadas no Jornal do Brasil entre 1967 e 1973 -, texto oportuno para abordar aqui a crença numa racionalidade claudicante:

Talvez tenha sido o meu maior esforço de vida: para compreender a minha não inteligência, o meu sentimento, fui obrigada a me tornar inteligente (Usa-se a inteligência para entender a não inteligência. Só que depois o instrumento - o intelecto -, por vício do jogo, continua a ser usado e não podemos colher as coisas de mãos limpas, diretamente na fonte). ${ }^{23}$

\footnotetext{
${ }^{21}$ Remeto o leitor novamente ao ensaio de Berta Waldman, onde se lê a bela síntese do que foi desdobrado aqui: "O conto 'A menor mulher do mundo' desfaz o tempo todo a intenção etnocêntrica daqueles que estão empenhados em apagar a diferença, desmascarando as tentativas de reduzir o outro ao mesmo, e de discriminar a diferença como inferior ou aberrante. Ao mesmo tempo que se desconstrói um modelo cristalizado de racionalidade, de cultura, de ciência, emerge o exame do informe, da matéria humana minúscula, quase reduzida a nada, e, no entanto, pulsante. Emerge a metáfora da história do feminino, das relações homem/mulher, história feita de submissão e luta, delicadeza e medo. Isso tudo é desenhado na complexa interação homem/mulher. Se, por um lado, o trabalho do explorador é o de tentar afastar a pigmeia da espécie humana, de outro, o movimento da pigmeia é ode impor sua humanidade despossuída de acréscimos civilizacionais, espécie de humanidade em estado puro" (WALDMAN, op. cit., p. 64-65, grifos da autora).

${ }^{22}$ LISPECTOR, op. cit., 1991, p. 96.

${ }^{23}$ LISPECTOR, op. cit., p. 414.
} 
Para a autora, provavelmente nem o intelecto e nem a salvação divina aplacam a angústia de experimentar o "Unheimliche" da vida ou apaziguar o que não tem nome. Colher uma "pequena flor" diretamente na fonte talvez não seja tão fácil sem um bloco de notas. O instrumento simbólico da inteligência, da linguagem que contorna o Real ${ }^{24}$ pode apenas aproximar-se do que já nos foi familiar e do qual nos distanciamos pelo efeito mesmo da construção cultural. Restou-nos, porém, a literatura, um modo de ouvir "a palavra fora do poder" - como afirma Roland Barthes em sua conhecida Aula ${ }^{25}$ E para os que carecem de um bloco de notas, por um lado, ou da literatura, por outro, sempre existe a solução “ex-machina", capaz de proteger os aflitos: "Deus sabe o que faz".

\footnotetext{
${ }^{24}$ A conceituação lacaniana do Real abriria uma outra perspectiva analítica para o conto, próxima a que desenvolvemos aqui, mas que exigiria outro ensaio. Para o momento, remeto o leitor à ideia de Real como tudo o que não é apreensível pela rede da linguagem simbólica, permanecendo como indizível e irrepresentável. Daí sua condição de resíduo que retorna sempre, pois "não cessa de não se escrever". Devido ao impacto de sua assustadora intensidade e do incômodo que geral com sua incognoscibilidade, habitamos os campos do Imaginário (mediações formadoras do Eu) e do Simbólico (lugar das palavras, dos significantes e do discurso). A esse respeito, ver LACAN, Jacques. O Seminário. In: da psicanálise". Tradução de Antonio Quinet. Rio de Janeiro: Jorge Zahar, 1988, livro 7.

25 "Mas a nós, que não somos nem cavaleiros da fé nem super-homens, só resta, por assim dizer, trapacear com a língua, trapacear a língua. Essa trapaça salutar, essa esquiva, esse logro magnífico que permite ouvir a língua fora do poder, no esplendor de uma revolução permanente da linguagem, eu a chamo, quanto a mim: literatura" (BARTHES, Roland. Aula. Trad. Leyla Perrone-Moisés. São Paulo, Cultrix, 2004, p. 15).
} 